\title{
APRENDER NA ESCOLA PARA ALÉM DA SALA DE AULA: COMUNIDADES DE PRÁTICA, PARTICIPAÇÃO PERIFÉRICA LEGÍTIMA E ESPAÇOS DE AFINIDADE NO AMBIENTE ESCOLAR FORMAL
}

\author{
Cláudio Roberto Antunes Scherer Júnior
}

Mestre em Educação pela Universidade Federal de Santa Catarina - UFSC, linha de pesquisa Sociologia e História da Educação, Florianópolis, SC. E-mail: claudioschererir@yahoo.com.br

\section{RESUMO}

O ambiente formal de ensino é um local de variadas formas de construção de conhecimento. Isso pode ser constatado no cotidiano de qualquer instituição escolar em que as interações entre estudantes são constantes e, portanto, as trocas de ideias também. A intenção deste artigo é problematizar sobre os momentos não considerados propriamente de ensino/aprendizagem, momentos extraclasses que podem se tornar fonte de conhecimentos importante para a vida dos estudantes. Para isso, alguns autores de diferentes áreas de conhecimento são mobilizados, principalmente, Lave e Wenger (1991) que trabalham com o conceito de participação periférica legítima e comunidades de prática, e, Gee (2004) que articulas as ideias anteriores ao contexto interconectado da atualidade por meio dos espaços de afinidade. Memórias pessoais do autor auxiliaram a pensar sobre algumas formas de aprendizagem extraclasse possíveis em ambiente escolar formal. Parece ser fundamental o desafio de superar a hegemonia da aprendizagem escolarizada, bem como do exclusivismo dos conteúdos escolares como únicas fontes de conhecimento, em detrimento das aprendizagens fruto de interações humanas.

Palavras-chave: Ambiente escolar formal. Comunidade de prática. Participação periférica legítima. Espaços de afinidade.

\section{LEARNING IN SCHOOL BEYOND THE CLASSROOM: COMMUNITIES OF PRACTICE, LEGITIMATE PERIPHERAL PARTICIPATION AND AFFINITY SPACES IN THE FORMAL SCHOOL ENVIRONMENT}

\begin{abstract}
The formal teaching environment can be a place of various forms of knowledge building. This can be verified in the daily life of any school institution, where the interactions between students are constant and, therefore, the exchanges of knowledge as well. The intention of this article is to problematize on moments not considered as teaching / learning, extraclass moments that can become important knowledge source for students' lives. For this, some authors from different areas of knowledge are mobilized, mainly Lave and Wenger (1991) who work with the concept of legitimate peripheral participation and communities of practice, and, Gee (2004) that articulate the previous ideas to the interconnected context of present through the affinity spaces. The author's personal memories helped to think about some forms of extraclass learning possible in a formal school environment. The challenge of overcoming the hegemony of schooling, as well as the exclusivism of school contents as the only sources of knowledge, to the detriment of learning resulting from human interactions seems to be fundamental.
\end{abstract}

Keywords: Formal school environment. Community of practice. Legitimate peripheral participation, Affinity spaces.

\section{INTRODUÇÃO}

A instituição escolar é fonte de diversos tipos de conhecimento, mas, de modo específico, ela oficializa conhecimentos formais que são sancionados através de diplomas. Esses seriam o 'passaporte' para o próximo estágio, seguindo o caminho da educação formal.

Ao pensar sobre a escola enquanto um espaço de formação de pessoas, ou seja, indivíduos cada qual único, é possível constatar 
uma série de problemas e desafios, pois afinal, o modelo escolar ainda vigente remete-nos ao século XIX e, mesmo após todo o tempo transcorrido desde então, a instituição escolar ainda se mantém presa a alguns padrões e ideais. É evidente que alguns ajustes foram feitos, porém, grosso modo, nossa escola continua muito semelhante à de séculos passados.

Illich (1977) já apontava alguns problemas ligados não só a escola, mas ao modelo escolarizado de sociedade que deslegitima outras formas de busca por conhecimentos. Mais recentemente, a antropóloga e comunicóloga Sibilia (2012) caracterizou a escola como sendo um aparato tecnológico de época, e, portanto, fora de contexto em nossa atual sociedade informatizada.

Afinal, teria a escola, apesar de todos os problemas, outras possibilidades de aprendizagens não tangenciadas pela formalidade? Aprendizagens que apesar de inseridas em meio aos contextos formais de ensino, possibilitariam o desenvolvimento de habilidades e saberes tão importantes para a vida em sociedade quanto os conteúdos presente nos rígidos currículos? Essa é a pergunta central deste artigo, localizar e problematizar sobre teorias e possibilidades de outras formas de aprendizagens que possibilitem outros tipos de conhecimentos em contextos de ambientes escolares considerados formais, ou seja, na escola 'tradicional'.

Por não possuir nenhum tipo de dado de campo que possibilite exemplificar o que será exposto neste artigo, será tomada a liberdade para explorar algumas lembranças de momentos de minha própria experiência de vida, mais especificamente, será utilizado como exemplo para a reflexão alguns momentos e situações de meus primórdios no Ensino Médio. Momento marcante em minha vida devido a uma drástica mudança de escola com a consequente adaptação nesse novo, e para mim inóspito, ambiente.

Para a empreitada deste artigo foi utilizada uma metodologia de pesquisa bibliográfica e rememorativa. Num impulso interdisciplinar, foram trabalhadas uma miscelânea de pesquisas de autores das áreas de Antropologia, Comunicação, Psicologia e Educação. A intenção foi analisar e compreender situações e momentos de minha experiência enquanto estudante por meio das lentes dos conceitos de participação periférica legítima e comunidades de prática, cunhados por Lave e Wenger (1991), e, analisar os desdobramentos ligados ao mundo informatizado desses conceitos por meio do avanço de compreensão a respeito dos espaços de afinidade conforme pensado por Gee (2004). Além desses autores, outros, tais como: Illich (1977) e Sibilia (2012), já citados, e também as ideias de Freire $(1983 ; 1999)$ e Tassinari $(2012$; 2015) que tratam sobre a educação em múltiplos vieses, foram também mobilizados e articulados.

\section{Ensinar sem querer, aprender sem saber}

As reflexões deste artigo partem da ideia de ser possível aprender além do que é especificado nos currículos no ambiente escolar formal. Apesar das dificuldades ao pensar a escola enquanto um lugar de construção de conhecimento, principalmente conhecimento autônomo e personificado, ou seja, conhecimento realmente significante para as vidas dos sujeitos envolvidos, talvez, seja possível pensar a escola também como um local de aprendizagem informal, um local de trocas entre estudantes, entre pessoas. Portanto, algo além da relação unilateral e hierarquizada entre professor (mestre) e aluno (aprendiz). Algo semelhante ao encontrado por Codonho (2007 apud TASSINARI, 2012) em sua dissertação sobre a transmissão de saberes entre as crianças indígenas Galibi-Marworno. Segundo a autora, as crianças desse grupo indígena são fundamentais para a aprendizagem dos mais jovens sobre determinados assuntos, o que "inclui as crianças numa rede ampla de transmissão de conhecimentos, saberes, habilidades, técnicas, não somente como aprendizes, mas também como mestres." (CODONHO, 2007 apud TASSINARI, 2012, p. 284). Talvez, uma situação parecida, porém, em menor grau, pode ser possível num ambiente escolar formal não indígena. Uma transmissão de conhecimentos e saberes entre membros de um mesmo grupo, sem hierarquias marcantes, num contexto não explícito de aprendizagem.

Para ilustrar melhor o que se pretende dizer, peço licença para um pequeno 'flashback' de minha história pessoal como estudante.

Ao terminar meus estudos no Ensino Fundamental, minha família conseguiu vaga numa das maiores escolas pública da América Latina, na capital do Estado de Santa Catarina, Florianópolis. Parecia ser uma boa ideia, pois 
sairia de uma pequena escola de bairro, para uma grande instituição no centro da cidade. Em nenhum momento pensei nas dificuldades e desafios que enfrentaria ao trocar uma escola que atendia cerca de 300 estudantes, para uma instituição com mais de 5 mil.

Porém, na primeira semana de aula, sem conhecer ninguém, acabei sendo alvo de alguns alunos que furtavam pertences dos estudantes. Fiquei marcado e a partir de então não conseguia ficar tranquilo na escola e arredores. Estava sempre com pressa e com medo.

Passadas algumas semanas de apreensão e desespero, quando eu já estava quase contando tudo para meus pais, com o intuito de pedir para mudar de escola, comecei uma amizade com um colega de sala que era parente e amigo daqueles que me furtavam. Logicamente que eu nada sabia a respeito dessa ligação parental. Só tomei conhecimento quando ao descer para o intervalo meu amigo me levou até o grupo dos estudantes que me incomodavam. Cumprimentamo-nos e ficamos com eles. A partir daquele momento, minha situação de alvo dos furtos e intimidações acabou, pois fui aceito no grupo.

Logicamente eu não participava dos furtos e intimidações. Eu apenas comecei a aprender como as coisas funcionavam nessa minha nova escola. Para meu próprio bem eu precisava estar dentro de um grupo, pois assim não estaria sozinho e não seria alvo desses pequenos furtos. Com esses meus novos colegas, com os quais sempre tive receios, aprendi sobre inúmeras coisas sem necessariamente alguém me ensinar. Apenas vendo e ouvindo como eles falavam, se vestiam e se portavam fui aprendendo e tentando reproduzir algo semelhante.

Ao relatar de modo resumido essa minha experiência, é interessante perceber como à época tudo parecia mais intenso, os problemas maiores e a solução tão distante, lógico, era a adolescência. Ao rememorar essa história e pensar sobre os acontecidos, percebi que talvez eu tenha conseguido entrar numa comunidade de prática, aos moldes do exposto por Lave e Wenger (1991), e enquanto membro dessa comunidade, observando e vivenciando, adquiri uma série de conhecimentos, práticas e saberes.

Hoje isso parece mais claro, devido a distância temporal e uma série de estudos e experiências que nos fazem perceber nuances antes não perceptíveis. É possível supor que ao ser aceito na comunidade dos que intimidavam e furtavam estudantes, eles, foram meus mestres sem ter essa intenção. Obtive conhecimentos deles através de uma "participação periférica legítima".

Segundo Lave e Wenger (1991, p. 40),
devemos enfatizar que a
participação periférica
legítima não é em si uma
forma educativa, muito
menos uma estratégia
pedagógica ou uma
técnica de ensino. É um
ponto de vista analítico
sobre a aprendizagem,
uma maneira de entender
a aprendizagem.
(Tradução minha)

Assim como aconteceu comigo, acredito que a escola possui vários outros momentos de aprendizagem periférica. $O$ ambiente escolar para além da sala de aula é extremamente frutífero para socializações entre estudantes de diferentes idades, condições financeiras, de diferentes localidades, com diferentes concepções e estilos de vida.

Illich (1977) acreditava nas possibilidades de uma sociedade desescolarizada, onde pessoas com interesses em comum se encontrassem e compartilhassem de modo voluntário seus conhecimentos. Para Illich (1977, p. 76) "a aprendizagem é a atividade humana menos necessitada de manipulação por outros. Sua maior parte não é resultado da instrução. É antes, resultado de participação aberta em situações significativas." A escola possibilita uma série de encontros extraclasse que fomenta participações abertas: os momentos antes do início das aulas, o entre aulas, o recreio, as atividades esportivas, as gincanas e jogos escolares, o pós-aula; e mesmo situações durante as aulas propriamente ditas, ou seja, conversas paralelas, trocas de informações via smartphones, ou mesmo os antigos papeizinhos passados de carteira em carteira, possibilitam comunicações e diálogos entre grupo de estudantes com interesses e afinidades em comum.

Illich (1977, p. 37) afirma ainda que o sistema escolar repousa sobre uma grande ilusão de que

\footnotetext{
1 "We should emphasize, therefore, that legitimate peripheral participation is not itself an educational form, much less a pedagogical strategy or a teaching technique. It is an analytical viewpoint on learning, a way of understanding learning."
} 
a maioria do que se aprende é resultado do ensino. $\mathrm{O}$ ensino, é verdade, pode contribuir para determinadas espécies de aprendizagem sob certas circunstâncias. Mas a maioria das pessoas adquiri a maior parte de seus conhecimentos fora da escola.

É possível pensar esse "fora da escola" apontado pelo autor, não apenas como o fora dos muros da escola, ou seja, do espaço físico escolar. Mas também um fora do ambiente formal de ensino, fora da instrução de sala de aula. Permitindo, desse modo, uma margem para pensarmos as "escolas enquanto espaços de/para encontro de parceiros" (ILLICH, 1977, p. 151).

A partir desses encontros, as aprendizagens mútuas entre membros das mesmas comunidades se tornam não apenas mais significativas, como elas acabam nem sendo percebidas enquanto construção de conhecimentos, de saberes importantes para as vidas dos indivíduos.

\section{Das comunidades de prática aos espaços de afinidade}

A antropóloga Tassinari (2015), num artigo sobre a aprendizagem entre crianças indígenas e agricultoras em contextos não escolarizados, assinala para a ideia de que a escola não constitui uma fonte hegemônica de conhecimento, que outras situações vivenciadas, principalmente, através da participação em atividades produtivas familiares podem resultar em aprendizagem.

Apesar de contextos diferentes, é possível apontar para a existência dessas situações vividas em ambiente escolar também como fonte de aprendizagem: "Uma educação silenciosa, que quase não faz recurso à palavra, que ocorre nos contextos de prática [...]" (TASSINARI, 2015, p. 166). No caso da antropóloga o ambiente agrícola do interior do Paraná e entre determinado grupo indígena no Amapá. No caso deste artigo os ambientes escolares formais de modo geral.

Tassinari (2012) ao propor outros modos de conceber a aprendizagem, além do modelo escolarizado de nossa sociedade, critica as motivações daquilo que se impõem no ensino formal. Segundo a antropóloga: "Estuda-se o que vai cair na prova e, no extremo, os conhecimentos ganham importância na medida em que são assunto do vestibular". (TASSINARI, 2012, p. 279). Essa afirmação parece caminhar conjuntamente com as críticas a respeito da educação bancária apontada por Freire (1983, p. 69) "que anula o poder criador dos educandos ou o minimiza, estimulando sua ingenuidade e não sua criticidade". Para ele o importante "de uma educação libertadora, e não 'bancária', é que, em qualquer dos casos, os homens se sintam sujeitos de seu pensar, discutindo o seu pensar, sua própria visão de mundo." (FREIRE, 1983, p. 141). Algo totalmente indiferente aos vestibulares, provas e demais tipos de avaliações.

Os conteúdos curriculares não teriam me ajudado na situação em que me achava no início do Ensino Médio. E, apesar da aprovação, pois fui relativamente bem nas provas e avaliações dos conteúdos apresentados em sala de aula, o meu problema àquela época não era nada relacionado às disciplinas, ele era outro, e a solução veio junto de interações humanas, de relações interpessoais, da inserção em uma comunidade e dos conhecimentos construídos a partir da minha participação periférica no grupo que outrora me perturbava. Os conhecimentos adquiridos naquelas relações podem não ser mais diretamente úteis, porém, foram essenciais para minha construção enquanto estudante e enquanto sujeito.

O conceito de participação periférica legítima obtém seu significado, não de uma concisa definição de seus limites, mas sim de suas múltiplas interconexões, gerados por teoria, com pessoas, atividades, conhecimento e mundo. [...] Esta concepção maior e mais ampla do que significa aprender, que propõe o conceito de participação periférica legítima, trata de abarcar a rica significação da aprendizagem na experiência humana. (LAVE; WENGER, 1991, p. 121. Tradução minha). ${ }^{2}$

\footnotetext{
2 "The concept of legitimate peripheral participation obtains its meaning, not in a concise definition of its boundaries, but in its multiple, theoretically generative interconnections with persons, activities, knowing, and world. [...] This longer and broader
} 
A partir dessa afirmação podemos compreender os ambientes escolares não formais, os lugares de conversa e de trocas de ideias que podem ser considerados banais como significativos da experiência humana e a participação periférica legítima como um modo de conceber esse tipo de aprendizagem.

Freire (1983) também apontava para a importância da experiência para determinados tipos de aprendizado. Situações onde nenhuma teoria poderia suprir as necessidades empíricas e de modo muito simples afirmou que "um homem não aprende a nadar numa biblioteca, mas na água." (FREIRE, 1983, p. 160). Assim, é possível pensar que não nos tornamos seres sociais e socializáveis através de conteúdos estáticos, numa relação unilateral em um ambiente formal de ensino, mas somos quase que forçados a buscar socializações ao nos depararmos com problemas e situações nas quais sozinhos não alcançaríamos soluções. E para isso, os mestres não têm diplomas, nem são legitimados por uma instituição. Podem ser os colegas mais experientes, que numa participação periférica transmitem, sem saber, seu modo de lidar com situações e problemas reais, ligados a vida cotidiana intramuros da escola e algumas vezes também fora desses muros.

A crítica à escola, ao modelo escolar, às práticas didáticas, à estrutura física, ao atraso tecnológico, ao modelo de educação não é nenhuma novidade. Illich (1973), Freire (1983, 1999) já o faziam desde antes da década de 1970. Se ainda fossem vivos, veriam que ainda estamos, em parte, muito distantes daquilo que almejavam. Mesmo autores recentes como Sibilia (2012), que pensa a escola em meio ao caos da fluidez da contemporaneidade e que localiza a instituição escolar dentro de um turbilhão de informações no atual mundo conectado as redes, não consegue visualizar e prever os caminhos que essa instituição pode e deve tomar no futuro.

Ao pensar sobre o atual contexto escolar é possível constatar uma grande e marcante diferença entre a escola problematizada por Freire (1983, 1999) e Illich (1977) na segunda metade do século XX e também a escola da qual eu fiz parte no início dos anos 2000: a proliferação e popularização das tecnologias de informação e comunicação (TIC). Na atualidade, fazer parte de um grupo, de uma comunidade,

conception of what it means to learn, implied by the concept of legitimate peripheral participation, comes closer to embracing the rich significance of learning in human experience." pode estar muito mais ligado às redes sociais e à aplicativos de smartphones, do que estar presencialmente entre sujeitos de 'carne e osso'.

Foi justamente a partir dessa constatação que Gee (2004) propôs um avanço na compreensão daquilo que Lave e Wenger (1991) nomeava como comunidades de prática. Para Gee (2004), o novo contexto de comunicação proporcionado pelas TIC está além de espaços físicos, onde membros de grupos se encontram e conscientemente ou inconscientemente, compartilham informações e conhecimentos. Gee (2004) concebia as comunidades de prática como importante força de aprendizagem, porém, sugere o conceito de espaços de afinidade mais apropriado e compatível com a fluidez e instabilidade do mundo interconectado.

Uma das principais características desses espaços de afinidade é a possibilidade de diversas formas de interação não necessariamente ligados a um espaço físico, seja ele um clube, um país, uma escola, etc. Ambientes virtuais: websites, videogames, chats, redes sociais, entre outros, são justamente os melhores exemplos desses espaços de afinidade. (GEE, 2004).

Dois aspectos parecem ser centrais para falar de espaços de afinidade: "esforço e interesse" (GEE, 2004, p. 77). Num espaço de afinidade é a partir de interesses individuais, impulsionados pelo esforço pessoal que despertam os sujeitos para a construção de conhecimento, motivados pela possibilidade de interação com outras pessoas também interessadas, gerando uma troca de conhecimentos e experiências. Nessa parte, podemos constatar semelhanças entre as ideias de Gee (2004) e aquilo que Illich (1977) escreveu nos anos de 1970: "A mais radical alternativa para a escola seria uma rede ou um sistema de serviços que desse a cada homem a mesma oportunidade de partilhar seus interesses com outros motivados pelos mesmos interesses." (ILLICH, 1977, p. 47. Grifo meu).

Illich (1977) escreveu esse texto muito antes dos primórdios do que hoje chamamos de redes sociais, mas sua ideia parece justamente prognosticar aquilo que Gee (2004) nomeou de espaços de afinidade. $O$ grande contraste de sua afirmação é que essas "redes" não se tornaram, ainda, uma alternativa à escola, antes sim, uma alternativa à busca por conhecimento.

O modo de conceber os espaços de afinidade de Gee (2004) parece mais compatível com o desenrolar das relações humanas em 
nossa atual sociedade conectada as redes. E, logicamente, a escola absorve de algum modo essas transformações.

Mesmo de diversas formas, concebidas em diversas teorias diferentes, ou mesmo apesar da massiva crítica; mudam-se os meios, porém, diálogo e mediação, ainda são as palavras chave para a compreensão dos processos de ensino e aprendizagem. Sejam os espaços de afinidade, as comunidades de prática, situações de participação periférica legítima e contextos não escolarizados de aprendizagem; todos são formas interessantes de pensar e problematizar algumas concepções arraigadas quando tratamos de aprendizagem e de ambiente escolar de ensino. Essas diferentes concepções auxiliam na compreensão dos contextos escolares e não escolares de construção de conhecimento, pois geram possibilidades e formas de ver os processos educativos através de outros vieses. Auxiliam no objetivo de pensar uma sociedade "contra uma homogeneização da educação escolar como forma exclusiva de aprendizagem e dos conhecimentos escolares como fontes únicas de sabedoria." (TASSINARI, 2012, p. 288).

\section{CONSIDERAÇÕES FINAIS}

Ao longo das linhas deste artigo a intenção foi apresentar e debater algumas ideias novas e antigas a respeito de ensino, aprendizagem e de escola. Pode-se constatar que independente do tipo de abordagem: antropológica, sociológica, linguística, pedagógica; enfim, não importa a área de conhecimento, os desafios da compreensão dos processos educacionais serão sempre difíceis. 0 ambiente escolar formal possui várias nuances, 0 que torna sua problematização sempre um desafio cada vez maior, pois abarcar todas as possibilidades é uma tarefa impossível.

Pensar a escola enquanto um ambiente de interações, onde diferentes sujeitos trocam ideias, conhecimentos e saberes, um lugar que proporciona diálogos e comunicações de experiências sobre os mais variados assuntos e imaginar tudo isso ocorrendo sem um controle direto, ou mesmo sem uma supervisão de um professor, pode parecer para alguns uma atividade infrutífera e sem sentido, pois, de maneira geral, é comum pensar que aquilo que realmente tem validade é 'transmitido' de modo oficial através do professor, através do livro didático, ou seja, de métodos e meios legitimados em uma aprendizagem formal.
Porém, o relato da minha experiência serve com exemplo de um tipo de desafio enfrentado diariamente por estudantes em qualquer lugar. Os problemas, como no exemplo apresentado, são muito mais marcantes e significantes para os indivíduos do que qualquer tipo de conteúdo de matemática, biologia e história. Relegar esse tipo de aprendizagem a algo com pouco valor e de menor importância, é negar o valor que a experiência da ação cotidiana da vida de cada um possui na construção de conhecimento individualizado. Trazer esses tipos de problemas cotidianos para os diálogos em sala de aula é uma forma de tornar mais útil e mais interessante os trabalhos dentro de uma escola.

As comunidades de prática, bem como os espaços de afinidade são modos de se conceber as relações humanas de aprendizagens presentes em nossa sociedade. E o modelo de escola e de ensino que ela propõe não poderia ficar a parte disso. Estamos constantemente aprendendo, seja de modo direto e intencional, seja através de uma participação periférica legítima. A grande diferença é o valor social e pessoal dado a cada um desses momentos.

Por tudo isso, parece ser tão difícil não concordar com Tassinari (2012), quanto a suposta homogeneização da educação escolar como forma exclusiva de aprendizagem e dos conhecimentos escolares como fontes únicas de sabedoria. Lutar contra essa suposta 'verdade' é dever de todo aquele preocupado com o desenvolvimento do ser na busca de sua plenitude.

Independente se presencialmente ou não, se a partir de estruturas não lineares de ensino, se tendo computadores como professores, ou mesmo uns aos outros como mestres; uma coisa não mudará, a necessidade de diálogo, de grupos, comunidades, de espaços de afinidade, de momentos extraclasses. Locais e momentos onde é possível comunicar e interagir com pessoas e a partir disso construir conhecimento para si. Afinal, como afirmou Freire (1983, p. 79): "ninguém educa ninguém, como tampouco ninguém se educa a si mesmo: os homens se educam em comunhão, mediatizados pelo mundo. " $E$ isso ainda faz muito sentido, apesar das transformações tecnológicas da humanidade. 


\section{REFERÊNCIAS}

FREIRE, Paulo. Pedagogia da autonomia: saberes necessários à prática educativa. São Paulo: Paz e Terra, 1999.

Pedagogia do oprimido. Rio de Janeiro:

Paz e Terra, 1983.

GEE, James Paul. Introduction; Affinity Spaces. In: - Situated Language and Learning: A critique of traditional Schooling. New York, London: Routledge, p. 01-04; 70-81. 2004. Disponível em: <http://networkedlearningcollaborative.com/wpcontent/uploads/2015/07/james-paul-geesituated-language-and-learning-a-critique-oftraditional-schooling-2004.pdf.> Acesso em: 16 out. 2018.

ILLICH, Ivan. Sociedade sem escolas. Petrópolis: Vozes, 1977.

LAVE, Jean; WENGER, Etienne. Situated Learning: legitimate peripheral participation. Cambridge: Cambridge University Press, 1991. Disponível em: <https://www.cambridge.org/core/books/situate d-

learning/6915ABD21C8E4619F750A4D4ACA616C D>. Acesso em 16 out. 2018: DOI.

10.1017/СВO9780511815355.

SIBILIA, Paula. Redes ou paredes: a escola em tempos de dispersão. Rio de Janeiro: Contraponto, 2012.

TASSINARI, Antonella. A sociedade contra a escola. In: ___ et al. (orgs.) Educação Indígena: reflexões sobre noções nativas de infância, aprendizagem e escolarização. Florianópolis: EDUFSC, 2012. p. 275-294.

. Produzindo corpos ativos: a aprendizagem de crianças indígenas e agricultoras através da participação nas atividades produtivas familiares. In: Revista Horizontes Antropológicos. Porto Alegre, ano 21, n.44, p. 141-172. 2015. Disponível em: http://www.scielo.br/pdf/ha/v21n44/01047183-ha-21-44-0141.pdf Acesso em: 16 out. 2018.

Recebido para publicação em: 17/11/2017

Revisado em: 16/10/2018

Aceito em: 25/10/2018 